\title{
O Cantinho da Leitura como prática de letramento literário
}

\section{The Reading Corner as literary literacy practice}

\author{
Renata Junqueira de Souza* \\ Rildo Cosson**
}

\begin{abstract}
RESUMO
Por conta das preocupações pedagógicas com a formação do leitor, a literatura ensinada nos anos iniciais do ensino fundamental costuma sofrer um processo inadequado de escolarização. Todavia, esse cenário pode ser modificado quando se considera as especificidades do letramento literário. A análise do Cantinho da Leitura como uma prática de letramento literário neste nível de ensino demonstra que, mesmo em atividades tradicionais, é possível encontrar alternativas viáveis para a formação de um leitor literário.

Palavras-chave: Leitor Literário. Cantinho da Leitura. Leitura Independente Compartilhada. Letramento Literário. Formação do Leitor.
\end{abstract}

\begin{abstract}
Due the pedagogical concerns about reader formation, the Literature taught in the first cycle of elementary school usually suffer an inappropriate process of schooling. However, this scene can be changed when one takes the literary literacy approach. The analysis of the Reading Corner as a literary literacy practice in this level of teaching shows that even traditional activities can be turned in an well succeed alternative to the literary reader formation.

Keywords: Literary Reader. Reading Corner. Shared Independent Reading. Literary Literacy. Reader Formation.

* Universidade Estadual Paulista "Júlio de Mesquita Filho". Programa de Pós-Graduação em Educação. CELLIJ - Centro de Estudos em Leitura e Literatura Infantil e Juvenil. Presidente Prudente, São Paulo, Brasil. E-mail: recellij@gmail.com. https://orcid.org/0000-0003-2227-2544.

** Universidade Federal de Minas Gerais. Faculdade de Educação. CEALE - Centro de Alfabetização, Leitura e Escrita. Belo Horizonte, Minas Gerais, Brasil. E-mail: rcosson@gmail. com. https://orcid.org/0000-0003-2677-5149.
\end{abstract}




\section{Ensinar literatura nos anos iniciais do ensino fundamental}

É bem conhecido o ensaio de Magda Soares (1999) sobre a escolarização inadequada da literatura no ensino fundamental. Tomando como horizonte o livro didático, a autora aponta para uma seleção de textos inadequada, porque construída com pouca variedade de tipos, gêneros e fragmentos sem coerência e textualidade; assim como para atividades que pouco se preocupam com o caráter literário do texto, predominando abordagens informativas, formativas e gramaticais. Essa crítica ao modo como a literatura é inserida no livro didático também se faz presente em textos de diversos autores que abordam a questão de outras perspectivas (LAJOLO, 1982; ZILBERMAN, 1988; MOLINA, 1988; CHIAPPINI, 2005; PINHEIRO, 2009). Fazendo um histórico do livro didático enquanto instrumento de ensino da leitura ou formação do leitor no Brasil, Zilberman (2003) mostra como esse material de ensino termina implicando no relativo apagamento da literatura na escola. Nesse caso, o problema do livro didático não é apenas que seja constituído de textos mal recortados, mas também que, por seu inelutável caráter fragmentado, ele acaba por substituir a leitura do livro, que é o veículo preferencial da literatura. Do mesmo modo, Magnani (1989) destaca que os livros didáticos adotam como critério principal a seleção de textos curtos, e, consequentemente, apresentam uma coletânea de textos fragmentados, adaptados e textos escritos pelos próprios autores com intenções meramente didáticas, alguns com reprodução de textos de alunos que apenas repetem os modelos de escrita da escola. Esses textos, por sua vez, são acompanhados de ilustrações redundantes e de baixa qualidade, atividades de interpretação que apenas reproduzem trechos do texto lido e exercícios gramaticais. Com tal suporte, argumenta a autora, o ensino de literatura na escola dificilmente consegue formar o gosto pela leitura e pela escrita. Mais recentemente, em uma extensa análise de teses e dissertações sobre ensino da literatura no período de 1988 a 2006, Silva e Fritzen assinalam que um dos principais achados desses trabalhos acadêmicos é justamente a didatização inadequada do texto literário no livro didático. Nas palavras dos autores, sendo "alvo de críticas por parte de todas as pesquisas que o tomam por objeto de discussão, em linhas gerais, o livro didático apresenta concepções de texto e de leitura que acabam por eliminar o prazer estético" (SILVA; FRITZEN, 2012, p. 277). Tratando especificamente dos anos iniciais do ensino fundamental, Lima (2016) analisou os dois primeiros volumes de dez coleções de livros didáticos de Língua Portuguesa e verificou que persistem as condições inadequadas de escolarização da literatura já apontadas por outros estudos. A conclusão da 
autora é que não só as atividades com textos literários são inadequadas, como também o texto literário tem uma presença pequena nos livros didáticos. Logo, há um claro divórcio entre os livros didáticos e o uso pressuposto e desejado do texto literário na escola.

Todavia, não é só por conta do uso extensivo do livro didático em sala de aula que o ensino da literatura enfrenta percalços nos anos iniciais do ensino fundamental. Também a formação universitária dos professores não contempla o conhecimento específico da metodologia do ensino da literatura, quando muito os cursos de Pedagogia possuem em sua estrutura curricular uma disciplina dedicada à literatura infantil. Esse cenário é confirmado por Saldanha e Amarilha que, ao analisaram os currículos de Pedagogia de 27 universidades federais localizadas prioritariamente nas capitais dos estados, descobriram que menos da metade delas apresentava a disciplina Literatura Infantil, sendo mais usual a presença de uma disciplina optativa que é ofertada apenas esporadicamente. Para as autoras, que também assinalam a ausência ou silenciamento da literatura nas diretrizes curriculares do curso de Pedagogia, "os dados construídos indicam a pouca presença da literatura na formação de professores" (SALDANHA; AMARILHA, 2016, p. 390). Dessa forma, a despeito de uma herança histórica que evidencia a presença e a importância do ensino da literatura na formação de professores, como mostram, por exemplo, os manuais de Bárbara V. de Carvalho e Antônio D'Ávila (OLIVEIRA; TREVISAN, 2012) e a atuação de Lourenço Filho (BERTOLETTI, 2012), permitindo inclusive que se proponha uma história do ensino da literatura infantil (OLIVEIRA, 2015; 2016), o estatuto atual da literatura infantil nos currículos de pedagogia parece confirmar o que diz Peter Hunt, reconhecido estudioso do tema, no prefácio da edição brasileira de um de seus livros mais importante: "em muitos países, ela [a literatura infantil] tem uma existência precária e é encarada com ceticismo. Mesmo no Reino Unido, a disciplina literatura infantil é questionada" (HUNT, 2010, p. 12).

Essa ausência nos cursos de Pedagogia da literatura enquanto disciplina, e, logo, como espaço de reflexão, torna-se mais grave quando se sabe que, por conta de um percurso formativo pouco afeito à presença da literatura, os professores terminam por nãose constituírem como leitores literários (PORTO; PORTO, 2014). Quando muito, já no exercício da profissão, eles se tornam leitores de livros infantis, restringindo ou igualando seu repertório e horizonte de leitura ao de seus alunos. Nesse caso, para além da máxima de que não se forma leitor sem ser antes um leitor, como há muito apontam diversos estudiosos (SILVA, 1991; MORTATTI, 2014; COSSON, 2006), é preciso compreender, como bem faz Lígia Cademartori, que "muitos professores não tiveram as condições necessárias para se desenvolverem devidamente como leitores e, às vezes, pensam ser deficiência pessoal o que, na verdade, provém de âmbito muito mais amplo, 
como a dívida social do país com seu povo" (CADEMARTORI, 2009, p. 25); sabendo, ainda, que "tornar-se leitor é processo que ocorre ao longo do tempo e de distintas maneiras para diferentes pessoas" (CADEMARTORI, 2009, p. 24). Assim, mesmo reconhecendo que há professores que não são leitores, tal condição "não impede alguns deles de se empenharem honestamente na divulgação do livro entre os alunos e a trabalharem de modo a favorecer a outros melhor experiência de leitura que aquela que tiveram" (CADEMARTORI, 2009, p. 24)1.

Além do uso do livro didático e de um professor cuja formação passa ao largo da literatura e que termina por não se constituir como leitor literário, o ensino de literatura nos anos iniciais do ensino fundamental costuma padecer de uma ausência de especificidade enquanto matéria escolar nas orientações curriculares oficiais. Na maior parte desses documentos, a literatura não possui objetivos e práticas próprias, sendo simplesmente assimilada ao ensino de língua, no qual atua como mera coadjuvante. Nos Parâmetros Curriculares Nacionais, por exemplo, apesar de haver uma sessão intitulada "A especificidade do texto literário" (BRASIL, 1997), ela não resulta em uma orientação segura e objetiva. Ao contrário, como sintetiza pertinentemente Suassuna, trata-se de uma "abordagem meramente conceitual, centrada na forma do texto literário, sem nenhum tipo de desdobramento metodológico" (SUASSUNA, 1998, p. 180), além de silenciar sobre a escrita de textos literários na escola, tratando a literatura como matéria apenas de leitura ou da formação do leitor de maneira geral. Essa situação é bem diferente na recém lançada Base Nacional Comum Curricular - BNCC (BRASIL, 2017), que contempla um campo de atuação artístico-literário no qual se privilegia a formação do leitor literário, realizada por meio de práticas de leitura e produção de textos literários. Ainda assim, registra-se uma concepção de literatura infantil identificada restritivamente com o ludismo formal e o feérico, conforme se pode deduzir pelo uso de termos como "jogos de palavras" e "encantamento", e uma ênfase limitadora da fruição como leitura de prazer ou deleite.

Não é sem razão, portanto, que o ensino da literatura nos anos iniciais do ensino fundamental permanece preso a uma dupla perspectiva. De um lado, dentro de uma relação histórica que antecede e até mesmo dá origem à literatura infantil, está a perspectiva utilitária, presente mesmo naqueles momentos em que se enfatiza o interesse da criança, tal como aconteceu com a Escola Nova (COSTA, 2013). Trata-se do ensinar alguma coisa por meio do texto literário

1 A questão do professor não leitor tem suscitado diversas discussões no campo da Educação e das Letras, sobretudo quando se divulga enquetes e resultados de pesquisas referentes ao perfil de leitores no Brasil. Uma análise mais aprofundada do tema pode ser verificada no compêndio organizado por Marinho; Silva (1998). 
que, por ser atraente à criança, torna mais fácil a aprendizagem, numa atualização permanente e aparentemente inesgotável da fórmula horaciana do ensinar deleitando. Dessa forma, se atualmente não se considera mais o texto literário como meio de formação moral e orientador dos bons costumes como se fazia no passado, nem por isso se deixa de utilizá-lo com fins pedagógicos. Em uma análise de 140 relatos da observação de prática de contação de histórias em escolas de educação infantil e anos iniciais da região metropolitana de Porto Alegre, Kirchof e Silveira (2009) identificam três dimensões de pedagogização da literatura infantil: a escolha de textos que buscam "civilizar", ensinar algum comportamento, seja higiênico, seja social; a ênfase dada à mensagem da obra nos diálogos da professora com os alunos após a contação; e a seleção de obras que auxiliam outras questões da escola ou da turma. Daí a conclusão dos autores de que, de um modo geral, "a literatura infantil ainda não é concebida exclusivamente como um artefato estético pelos professores ligados às práticas de contação de histórias" (KIRCHOF; SILVEIRA, 2009, p. 214). Nessa mesma direção, compreende-se perfeitamente porque nos livros didáticos e nas orientações curriculares oficiais a literatura oral é progressivamente apagada à medida que o aluno avança nas séries do ensino fundamental. Afinal, ainda que apenas tacitamente reconhecido, mitos e parlendas se fazem presentes nesse momento na escola porque são gêneros literários que "colaboram" para o processo de alfabetização.

Por outro lado, até como uma reação ao utilitarismo, está a perspectiva idealista. Reconhecendo o caráter estético da literatura infantil que se produz a partir dos anos 1970, de uma geração herdeira de Lobato, tal como demarcou Perroti (1986), a perspectiva idealista defende que a melhor maneira de inserir a literatura na escola evitando os riscos da pedagogização é abster-se de qualquer propósito formativo, ou seja, apenas dando acesso às obras para que os alunos se "deleitem"com elas. Dessa forma, cabe ao professor somente o papel de mediador, no sentido de incentivador, da leitura, que deve ser feita em busca do prazer de ler, em semelhança ao que acontece com o leitor maduro, fora da escola. Também se argumenta que, como cada texto literário é único, não há nada a ser ensinado, apenas se deve oferecer o texto ao aluno e confiar no "encantamento" e na "viagem" da leitura do texto literário.

Aparentemente libertária, essa perspectiva idealista do "ler por ler" ou "ler por prazer” traz em si uma série de equívocos em relação à leitura literária. Um deles é ode que a leitura literária se faz espontaneamente, sem demandar nenhuma aprendizagem, esquecendo-se de que ler literatura, assim como qualquer outro texto, demanda o conhecimento de protocolos de leitura (SCHOLES, 1991) e que é responsabilidade da escola formar o leitor literário (oferta, escolha, etc.), tal como forma o leitor das demais matérias escolares, ou seja, cumpre ampliar e 
fortalecer o letramento literário do aluno. Outro é a questão da fruição entendida como uma atividade desinteressada, sem objetivo, numa aparente transposição da gratuidade do objeto artístico para o ato de ler, quando já aprendemos com Magda Soares (2005) que ler é verbo transitivo, no sentido de que leio sempre alguma coisa, sobre alguma coisa e por alguma razão, fatores que são determinantes do próprio ato de ler. Há, ainda, a questão do prazer entendido como inerente à leitura do texto literário. Aqui é preciso ter claro, como bem adverte Arena, tratando do leitor em geral, que "o prazer não é o sentimento definidor de um bom leitor, nem é o guia para ensinar a ler"e acrescenta que, "mesmo em Literatura, a leitura de um conto fantástico pode trazer ansiedade, medo, angústia como uma notícia de jornal pode trazer alegria, tristeza, inquietação" (ARENA, 2010, p. 245). Não menos simplificadora da leitura literária, por fim, é a orientação de que ao professor e à escola cabe apenas a disponibilização das obras, que o leitor literário se forma solitariamente a partir do contato com elas. Longe disso, conforme destaca Nikolajeva, "a evidência de crianças tendo acesso a livros e realmente examinando-os não implica necessariamente qualquer compreensão ou mesmo envolvimento mais profundo, especialmente em situações de sala de aula" (NIKOLAJEVA, 2010, p. 158).

Diante desse quadro tão pouco favorável ao ensino da literatura nos anos iniciais do ensino fundamental, é preciso que se reafirme, em primeiro lugar, a importância do letramento literário na escola como uma prática efetiva de formar leitores literários (COSSON, 2006; SOUZA; COSSON, 2011; COSSON, 2014). Depois, cumpre apontar caminhos que possibilitem fazer frente às dificuldades e aos empecilhos apresentados, sem deixar de reconhecer que vários deles são problemas estruturais e que ultrapassam a atuação docente e mesmo o ambiente escolar. Por fim, "é fundamental desenvolver na escola experiências planejadas de inserção dos estudantes no mundo da literatura. Experiências diversas podem ilustrar o quanto é possível e necessário realizar tal tipo de trabalho" (LEAL; ALBUQUERQUE, 2010, p. 95). É com base nesse conselho que apresentaremos a seguir uma prática específica de cantinho da leitura como uma proposta efetiva de letramento literário.

\section{O cantinho da leitura como estratégia de letramento literário na escola}

Muitas práticas de leitura podem auxiliar a ampliar e fortalecer o letramento literário na escola: círculos de leitura, dramatizações, leituras protocoladas, lei- 
turas guiadas, entre outras. Enfatizaremos nesse subitem uma prática específica que é bastante conhecida nas escolas de Ensino Fundamental, sobretudo em seus anos iniciais, assim como nos anos da Educação Infantil sob as denominações concorrentes de "biblioteca da sala", "estante mágica", "baú de leitura".

Fisicamente, o cantinho da leitura é composto com os livros dispostos em estantes, caixas e/ou baús - daí derivando as distintas denominações - na própria sala de aula para leitura individualizada dos alunos. Quanto menores são os alunos, mais bem elaborado é este espaço, podendo ir de almofadas com tapetes, confortáveis divãs, iluminação especial e itens diversos de decoração nas salas da Educação Infantil, até uma simples caixa deixada em um canto da sala de aula dos anos iniciais do Ensino Fundamental.

O acervo geralmente é constituído por títulos da biblioteca particular do professor, ou livros que os próprios alunos trazem a partir de uma lista previamente determinada ou escolhidos em casa pelos pais por solicitação da escola ${ }^{2}$. Há, ainda, escolas em que a própria biblioteca escolar envia e atualiza periodicamente os títulos da sala. A leitura acontece quando os alunos terminam alguma atividade e enquanto aguardam os colegas, pegam um livro. Ou, ainda, às vezes podem levar os livros da sala para lerem em casa.

O objetivo declarado de se oferecer a leitura diretamente em sala de aula e não na biblioteca ou até substituí-la quando não tem uma na escola é tornar os livros mais acessíveis para os alunos e, assim, incentivar a leitura independente ou leitura dita livre, porque, mesmo realizada no âmbito escolar, não recebe nenhuma orientação ou mediação por parte do professor. O objetivo não declarado é manter em silêncio ou pelo menos em outra ocupação os alunos que já terminaram a atividade proposta coletivamente e devem esperar pelos colegas para realizarem a próxima sem perturbar o conjunto da turma.

Nessas propostas de leitura "livre", traduzidas pelo cantinho da leitura tradicional, que representa a perspectiva idealista que destacamos acima, raramente há uma preocupação com a qualidade ou diversidade do acervo, até porque raramente há um trabalho de mediação de leitura, planejado nesse espaço e com esses títulos, ou seja, confunde-se o dar acesso ao livro com o trabalho pedagógico de formação do leitor literário. Ao chamar atenção para esse equívoco, não pretendemos, obviamente, recusar a leitura independente como atividade inadequada na escola, mas sim apontar para a insuficiência da simples oferta de obras literárias como prática de educação literária. É para mostrar o potencial

2 Ao tratar da invisibilidade das bibliotecas escolares em uma cidade de Goiás, Flomar Chagas destaca: "havia nas salas de aula o cantinho da leitura. Durante a matrícula, a secretaria da escola solicitava dos pais, se possível, um livro literário que no final do ano, passava, em forma de doação, ao acervo deste cantinho" (CHAGAS, 2016, p. 677). 
do cantinho da leitura que escolhemos relatar as atividades de um cantinho de leitura que motivou alunos a lerem, discutirem, escreverem e escutarem leituras e interesses alheios, inclusive com alunos que inicialmente diziam "odiar" ler, transformando-se em "devoradores" de livros.

\section{Um cantinho da leitura singular}

Trata-se de um cantinho da leitura elaborado pela professora Silvana Balsan para o quarto ano do Ensino Fundamental de uma escola municipal do interior do Estado de São Paulo. O objetivo inicial da docente era ter um espaço em que os alunos pudessem retirar livros para ler em casa, sem depender dos horários limitados e limitadores para formação do leitor, imposto pela biblioteca escolar. Segundo a professora "os discentes não podiam levar os livros para casa e o acesso à biblioteca limitava-se a um intervalo de 20 minutos em que os alunos liam os livros naquele local, em um único dia da semana" (BALSAN, 2018, p. 164). Soma-se a essa razão o fato de que as crianças só liam em casa através da "sacola viajante", um projeto da escola no qual um aluno por sala de aula levava um livro selecionado pela bibliotecária para ler em casa, podendo ficar com ele por até uma semana. Diante dessa falta de tempo com o livro, a professora Silvana Balsan notou ainda a limitação no material de leitura, geralmente um texto curto era selecionado para compor a "sacola viajante", eliminando livros mais extensos e histórias mais complexas.

A partir dessas constatações e da análise do perfil dos alunos em questionário específico, a docente se viu motivada a montar um cantinho de leitura. De um total de 19 discentes, 12 (63\%) afirmaram que o espaço onde mais liam era em casa. Dessa maneira, a professora sentiu a necessidade de criar um local de leitura para

[...] proporcionar às crianças acesso a um acervo do qual elas poderiam fazer empréstimos de livros para ler em casa e que, ao mesmo tempo influenciaria na formação leitora dos alunos e, concomitantemente, resolveria o problema da falta de livros para empréstimos e da dificuldade de ler, no ambiente escolar, livros mais extensos. (BALSAN, 2018, p. 166).

Uma das preocupações iniciais da professora foi com relação à diversidade do acervo. Para tanto, uma ação importante foi ouvir os alunos a respeito dos 
seus gostos, dos autores favoritos e, em meio aos livros considerados do cânone da literatura infantil, também foram adquiridos aqueles textos que as crianças haviam solicitado. Assim, o acervo preliminar foi comprado com recursos da própria docente somando 180 livros, sendo 130 livros de ficção e 50 de não ficção. Silvana Balsan (2018) afirmou que a quantidade de livros foi-se ampliando ao longo da ação de leitura proposta, em virtude das solicitações dos próprios alunos, pois, no decorrer do processo, vários deles adquiriram autonomia e liberdade para requerer outros títulos.

Elaborar um cantinho da leitura com todas essas particularidades revela que um leitor se constitui pouco a pouco, por isso é fundamental compreender que "é papel do professor partir daquilo que o aluno já conhece para aquilo que ele desconhece, a fim de se proporcionar o crescimento do leitor por meio da ampliação dos horizontes de leitura" (COSSON, 2006, p. 35). Afinal, quanto mais leituras um aluno acumula, maior será seu repertório e mais facilmente se amplia a sua competência de lidar com o universo da literatura.

Neste sentido, o acervo do cantinho da leitura foi constituído por livros de diversos gêneros (folclore, lendas, mitos, contos, poemas) e de vários autores brasileiros e estrangeiros, muitos selecionados pela professora, como obras de Lygia Bojunga, Marina Colassanti, Ruth Rocha, Ziraldo, Ricardo Azevedo, Perrault, Irmãos Grimm, Jon Sieszka, Roald Dahl, entre outros, e outros tantos atendendo apedidos dos alunos, a exemplo dos livros Diário de Julieta 2 e 3, de Ziraldo, a série Os detetives do prédio azul, de Flávia Lins e Silva, e ainda a coleção Diário de um Banana, de Jeff Kinney - as duas últimas adaptadas ao cinema e televisão. Nessa composição, observa-se que a docente soube negociar as suas expectativas de formação do leitor literário com as preferências de leitura manifestadas pelos alunos, compondo um acervo significativo para ambos.

Para dar início ao cantinho da leitura, a professora desafiou seus alunos na montagem do espaço e das próprias regras para seu funcionamento. A primeira atividade da professora consistiu em levar todo o acervo para sala de aula e pedir aos alunos para que, por meio da manipulação dos livros e da leitura dos paratextos, conhecessem os títulos que comporiam o cantinho da leitura. Essa atividade permitiu conversas paralelas a respeito dos livros desconhecidos ou que só eram do conhecimento de alguns. "Além disso, ao encontrarem os livros que os educandos haviam solicitado anteriormente e que gostariam de ler, eles se animavam e os mostravam para os companheiros, abraçando os volumes e afirmando aos colegas que eles seriam os primeiros a ler aquele volume especificamente" (BALSAN, 2018, p.181).

A seguir, a docente pediu para que os alunos a ajudassem na classificação dos livros, entre os de ficção e os de não ficção. Para tanto, as crianças escolheram as cores das etiquetas adesivas que sinalizaria tais textos, ou seja, os alunos 
participaram de todo processo de catalogação e puderam aprender, por meio do manuseio e leitura preliminar, as diferenças textuais. A professora relata uma conversa entre dois alunos, JJBJ e CCM:

- Como eu vou saber como separar os livros de ficção e de não ficção?

- Os livros de ficção contam uma história, como o conto de fadas, por exemplo.

- E o outro?

A aluna CCM pega o livro de não ficção e diz para o colega:

- Veja, o livro de não ficção tem subtítulos, fotos, mapas e fala sobre algo real: tipo dinossauros, sobre o mundo igual esse aqui.

A aluna folheia a obra junto com o colega e lhe mostra o que havia acabado de dizer. (BALSAN, 2018, p. 182)

Foi dessa maneira que os alunos foram se apropriando do espaço e dos livros por meio de ações como olhar, folhear, comentar e ler livremente. Assim, o cantinho da leitura possibilitou às crianças o acesso a um número variado de livros "para entender-se, para brincar, para ler inteiros, para olhar as ilustrações, para consultar palavras, para encontrar informações pontuais, etc." (COLOMER; CAMPS, 2002, p. 96).

Quanto aos empréstimos, a docente relata que, inicialmente, o cantinho da leitura funcionou todas as quintas-feiras, e os alunos tinham o tempo da aula para escolha e anotação do livro que estava sendo levado para casa em um caderno de registro. Um aluno "bibliotecário", que era alternado toda semana em um sistema de rodízio, ficava responsável pela chave e por cuidar de receber os livros da semana anterior. Com o passar do tempo, com a socialização das leituras, as crianças argumentaram com a professora que não haveria necessidade de os empréstimos acontecerem somente um dia na semana e nem de se retirar somente uma obra. Assim, os alunos passaram a pegar a chave de onde os livros ficavam guardados e monitorar, sozinhos, suas retiradas e suas escolhas.

É importante destacar que o papel da professora não foi apenas de montar o acervo, dar acesso aos livros e organizar o processo de empréstimo. Durante todo o funcionamento do cantinho da leitura, houve também um trabalho intencional de acompanhamento das leituras concretizadas. Foi praxe da docente conversar com cada uma das crianças em particular nos momentos de troca de livros, tentando perceber o que gostaram e dando palpites para as novas escolhas, com intenção de "iniciar um processo de evolução e ampliação dos horizontes de leitura dos alunos” (BALSAN, 2018, p. 173). Para a professora Silvana Balsan, 
foi importante abrir mão do controle da leitura e exercer o papel de mediadora, respeitando a escolha dos discentes, explicando que uma leitura poderia ser interrompida caso o aluno não gostasse e também, durante o diálogo sobre a obra lida, sugerir e debater novos livros para ampliação do repertório leitor, portanto uma ação individualizada que ajudou na construção da autonomia dos alunos.

Discutir sobre os livros no cantinho da leitura permitiu ainda que a docente percebesse os alunos classificados como "leitores relutantes", ou seja, aqueles que não demostram interesse na leitura, adotando uma atitude indiferente diante de atividades de leitura (JOBE; DAYTON-SAKARI, 1999). Durante os quatro meses de análise desse espaço específico de leitura na sala de aula, dos 19 alunos, 13 deles leram uma média de 14 livros, ou seja, 68\% superaram a média brasileira elencada pelo IBGE. Seis alunos foram classificados pela professora como leitores relutantes, entre eles dois aderiram ao projeto com muita animação, mas no decorrer do tempo foram demostrando atitudes que contrariavam essa situação inicial, fingindo terem lido as obras e até faltando às aulas nas quintas-feiras. A solução da professora foi trabalhar individualmente com esses alunos leitores relutantes em momentos específicos, buscando identificar a causa de sua dificuldade, descobrindo, por exemplo, que para um deles ler era somente oralizar o texto, logo a atividade de leitura individual e autônoma fora da sala de aula não fazia muito sentido. Outros enfrentavam problemas com as escolhas feitas por sugestão da professora e mesmo dos colegas porque não possuíam competência leitora suficiente para decifrar o código linguístico e ler textos mais extensos.

\section{À guisa de conclusão}

A intenção de relatar a experiência bem-sucedida da professora Silvana Balsan foi de ilustrar concretamente a possibilidade de superar a pedagogização da literatura na escola, criando e articulando projetos e espaços de leitura com uma prática de letramento literário viável na formação de um leitor com autonomia.

Nesse sentido, é importante enfatizar que essa autonomia é construída na rotina da sala de aula, como no exemplo da professora Silvana Balsan, que levou em consideração vários aspectos, entre eles: a elaboração de um cantinho da leitura com diversos tipos e gêneros, ou seja, uma ampla oferta; a participação dos discentes na montagem do espaço e das regras para sua utilização; o respeito às necessidades dos alunos e às suas escolhas e um momento de compartilha- 
mento da leitura individualmente com a docente e/ou com um colega por meio da indicação de novos títulos.

Estar atento a tudo que se passa na sala de aula em que se atua como professor não é tarefa fácil, pois tem-se que auxiliar nas dificuldades dos alunos, mostrando equívocos e maneiras de superá-los e, principalmente, alertando-os de que tudo faz parte de um processo e analisar a relação que o discente estabelece com o ato de ler através do diálogo e respeito ajuda a transformar a escola num espaço privilegiado e os alunos em autênticos leitores autônomos.

Afinal, como destaca Solé, "aprender a ler significa aprender a encontrar sentido e interesse na leitura. Significa aprender a se considerar componente para a realização das tarefas de leitura e a sentir a experiência emocional gratificante da aprendizagem" (SOLÉ, 1998, p. 172). O diálogo entre alunos e professor descrito nesse artigo mostra uma relação respeitosa e pessoal com o leitor, porque a docente partiu dos interesses de leitura dos discentes processualmente orientou novas leituras, sem impor textos, mas propondo obras de maneira motivadora e individualizada. Em síntese, olhando o leitor como um sujeito único, ativo e autônomo.

\section{REFERÊNCIAS}

ARENA, Dagoberto B. O ensino da ação de ler e suas contradições. Ensino em Re-Vista, v. 17, n. 1, p. 237-247, 2010. Disponível em: <http://hdl.handle.net/11449/115190>. Acesso em: 20 mar. 2014.

BALSAN, Silvana F. S. Nas veredas da leitura: ações para formação de leitores autônomos. 2018. 259 f. Tese (Doutorado) - Universidade Estadual Paulista, Faculdade de Ciências e Tecnologia de Presidente Prudente, Presidente Prudente, 2018.

BERTOLETTI, Estela N. M. Lourenço Filho e literatura infantil e juvenil. São Paulo: Editora Unesp, 2012.

BRASIL. Base Nacional Comum Curricular-BNCC. Brasília: MEC, 2017. Disponível em: <http://basenacionalcomum.mec.gov.br/>. Acesso em: 03 jan. 2017.

BRASIL. Secretaria de Educação Fundamental. Parâmetros curriculares nacionais: língua portuguesa. Brasília: MEC/Secretaria de Educação Fundamental, 1997.

CADEMARTORI, Lígia. O professor e a literatura: para pequenos, médios e grandes. Belo Horizonte: Autêntica, 2009. 
CHAGAS, Flomar A. O. A invisibilidade das bibliotecas escolares. CIAIQ2016: Atas: Investigação Qualitativa em Educação, v. 1, 2016, p. 672-680. Disponível em: <http:// www.proceedings.ciaiq.org/index.php/ciaiq2016/index>. Acesso em: 09 maio 2018.

CHIAPPINI, Lígia. Reinvenção da catedral: língua, literatura, comunicação: novas tecnologias e políticas de ensino. São Paulo: Cortez, 2005.

COLOMER, Teresa; CAMPS, Anna. Ensinar a ler, ensinar a compreender. Porto Alegre: Artmed, 2002.

COSSON, Rildo. Letramento literário: teoria e prática. São Paulo: Contexto, 2006.

COSSON, Rildo. O espaço da literatura na sala de aula. In: PAIVA, Aparecida; MACIEL, Francisca; COSSON, Rildo (Coords.). Literatura: ensino fundamental. Brasília: Ministério da Educação, Secretaria de Educação Básica, 2010. p. 55-68.

COSSON, Rildo. Círculos de leitura e letramento literário. São Paulo: Contexto, 2014.

COSTA, Aline S. Escola Nova e a literatura infantil na formação de professores: o caso do Instituto de Educação do Distrito Federal (1935-1937). Dia-Logos, Rio de Janeiro/ RJ, n. 7, p. 42-53, nov. 2013. Disponível em: <http://www.e-publicacoes_teste.uerj.br/ index.php/dia-logos/article/view/23279/16591>. Acesso em: 15 dez. 2017.

HUNT, Peter. Crítica, teoria e literatura infantil. Tradução de Cid Kinpel. São Paulo: Cosac Naify, 2010.

JOBE, Ron; DAYTON-SAKARI, Mary. Reluctant Readers: connecting students and books for successful reading experience. Ontario: Pembroke, 1999.

KIRCHOF, Edgar; SILVEIRA, Rosa M. H. Contação de história: uma análise da escolha de histórias em um recorte de experiências gaúchas. Conjectura, Caxias do Sul, v. 14, n. 2, p. 203-214, maio/ago. 2009. Disponível em: <http://www.ucs.br/etc/revistas/index. php/conjectura/article/view/24>. Acesso em: 15 dez. 2017.

LAJOLO, Marisa. Usos e abusos da literatura na escola: Bilac e a literatura escolar na república velha. Rio de Janeiro: Globo, 1982.

LEAL, Telma F.; ALBUQUERQUE, Eliana B. C. de. Literatura e formação de leitores na escola. In: PAIVA, Aparecida; MACIEL, Francisca; COSSON, Rildo (Coords.). $\mathrm{Li}$ teratura: ensino fundamental. Brasília: Ministério da Educação, Secretaria de Educação Básica, 2010. p. 88-106.

LIMA, Sheila O. Leitura literária no ciclo 1 do ensino fundamental: o livro didático como deflagrador de leitores precários. Cadernos de Letras da UFF. Dossiê: A crise da leitura e a formação do leitor, n. 52, p. 141-161, 2016. Disponível em: <http://www.cadernosdeletras.uff.br/index.php/cadernosdeletras/article/view/167>. Acesso em: 21 dez. 2017.

MAGNANI. Maria do Rosário. Leitura, literatura, escola. Sobre a formação do gosto. São Paulo: Martins Fontes, 1989. 
MARINHO, Marildes; SILVA, Ceris R. da. (Orgs.). Leituras do professor. Campinas: Mercado das Letras, 1998.

MOLINA, Olga. Quem engana quem? Professor x livro didático. 2. ed. Campinas, São Paulo: Papirus, 1988.

MORTATTI, Maria do R. L. Na história do ensino da literatura no Brasil: problemas e possibilidades para o século XXI. Educar em Revista, Curitiba, Brasil: Editora UFPR, n. 52, p. 23-43, abr./jun. 2014.

NIKOLAJEVA, Maria. Literacy, competence and meaning-making: a human sciences approach. Cambridge Journal of Education, v. 40, n. 2, p. 145-159, June 2010. Disponível em: <http://www.tandfonline.com/doi/abs/10.1080/0305764X.2010.481258>. Acesso em: 25 out. 2012.

OLIVEIRA, Fernando R. Compreender o passado para repensar o presente: a literatura infantil na história da formação de professores. Nuances: Estudos sobre Educação, v. 26, n. 3, p. 283-302, set./dez. 2015. Disponível em: <http://revista.fct.unesp.br/index. php/Nuances/article/viewFile/3703/3160>. Acesso em: 15 dez. 2017.

OLIVEIRA, Fernando R. Notas para uma história do ensino da literatura infantil na formação de professores primários no Brasil e em Portugal. Acta Scientiarum, v. 38, n. 1, p. 11-19, Jan.-Mar., 2016. Disponível em: <http://revista.fct.unesp.br/index.php/ Nuances/article/viewFile/3703/3160>. Acesso em: 15 dez. 2017.

OLIVEIRA, Fernando R.; TREVISAN, Thabatha A. A literatura infantil na formação de professores primários no Brasil: contribuições de Bárbara V. de Carvalho (1959) e Antônio D’Ávila (1961). Rev. Diálogo Educ., v. 12, n. 36, p. 359-379, maio/ago. 2012. Disponível em: <https://periodicos.pucpr.br/index.php/dialogoeducacional/article/ view/4615>. Acesso em: 15 dez. 2017.

PERROTTI, Edmir. O texto sedutor na literatura infantil. São Paulo: Ícone, 1986.

PINHEIRO, Hélder. Reflexões sobre o livro didático de literatura. In: BUNZEN, Clécio; MENDONÇA, Márcia (Orgs.). Português no ensino médio e formação do professor. São Paulo: Parábola Editorial, 2009. p. 103-116.

PORTO, Ana Paula T.; PORTO, Luana T. Da formação de professores à formação de leitores: desafios para uma prática eficiente de leitura na escola. Revista de Ciências Humanas - Educação, Frederico Westphalen, v. 15, n. 25, p. 94-107, dez. 2014. Disponível em: <http://revistas.fw.uri.br/index.php/revistadech/article/view/1595>. Acesso em: 15 dez. 2017.

SALDANHA, Diana M. L. L.; AMARILHA, Marly. Literatura e formação do pedagogo: caminhos que (ainda) não se cruzam. Desenredo, v. 12, n. 2, p. 376-396, jul./dez. 2016.

SCHOLES, Robert. Protocolos de Leitura. Lisboa: Edições 70, 1991.

SILVA, Danielle A. R.; FRITZEN, Celdon. Ensino de literatura e livro didático: uma abordagem a partir das pesquisas na pós-graduação brasileira. Revista Contrapontos - 
Eletrônica, v. 12, n. 3, p. 270, set.-dez. 2012. Disponível em: <https://siaiap32.univali. br/seer/index.php/rc/article/view/223 >. Acesso em: 15 dez. 2017.

SILVA, Ezequiel T. da. De olhos abertos: reflexões sobre o desenvolvimento da leitura no Brasil. São Paulo: Ática, 1991.

SOARES, Magda B. A escolarização da literatura infantil e juvenil. In: EVANGELISTA, Aracy et al. (Orgs.). A escolarização da leitura literária. Belo Horizonte: Autêntica, 1999. p. 17-48.

SOARES, Magda. Ler, verbo transitivo. In: PAIVA, Aparecida; MARTINS, Aracy; PAULINO, Graça; VERSIANI, Zélia (Orgs.). Leituras literárias: discursos transitivos. Belo Horizonte: Ceale; Autêntica, 2005. p. 127-144.

SOLÉ, Isabel. Estratégias de leitura. Porto Alegre: Artmed, 1998.

SOUZA, Renata Junqueira; COSSON, Rildo. Letramento literário: uma proposta para a sala de aula. São José do Rio Preto: Objetos Educacionais do Acervo Digital da Unesp, 2011. Disponível em: < http://acervodigital.unesp.br/bitstream/123456789/40143/1/01d 16t08.pdf>. Acesso em: 26 maio 2014.

SUASSUNA, Lívia. O que são e como se escreveram os parâmetros curriculares nacionais de língua portuguesa - o professor como leitor de propostas oficiais de ensino. In: MARINHO, Marildes; SILVA, Ceris R. da. (Orgs.). Leituras do professor. Campinas: Mercado das Letras, 1998. p. 175-184.

ZILBERMAN, Regina. A leitura e o ensino da literatura. São Paulo: Contexto, 1988.

ZILBERMAN, Regina. Letramento literário: não ao texto, sim ao livro. In: PAIVA, Aparecida et al. (Org.). Literatura e letramento. Belo Horizonte: Autêntica, 2003, p. 245-266.

Texto recebido em 08 de junho de 2018. Texto aprovado em 08 de agosto de 2018. 